\title{
Abnormal Indexes of Liver and Kidney Injury Markers Predict Severity in COVID-I 9 Patients
}

\author{
Jian Qu (iD) ${ }^{1, *}$ \\ Hai-Hong Zhu',* \\ Xue-Jian Huang' \\ Ge-Fei He ${ }^{2}$ \\ Ji-Yang Liu ${ }^{2}$ \\ Juan-Juan Huang ${ }^{2}$ \\ Ying $\mathrm{Chen}^{3}$ \\ Qiang $\mathrm{Qu}^{4}$ \\ Ya-Li Wu ${ }^{5}$ \\ Xiang-Yu Chen ${ }^{6}$ \\ Qiong Lu (D)'
}

'Department of Pharmacy, the Second Xiangya Hospital, Central South University; Institute of Clinical Pharmacy,

Central South University, Changsha,

4I00 II, People's Republic of China;

2Department of Pharmacy, The First

Hospital of Changsha, Changsha, 410005,

People's Republic of China; ${ }^{3}$ Department

of Pharmacy, Wuhan University, Renmin

Hospital, Wuhan, 430060, People's

Republic of China; ${ }^{4}$ Department of

Pharmacy, Xiangya Hospital, Central

South University, Changsha, 410007,

People's Republic of China; ${ }^{5}$ Department

of Pharmacy, Hunan Provincial Maternal

and Child Health Care Hospital,

Changsha, 410000, People's Republic of

China; ${ }^{6}$ Department of Radiology, the

Second Xiangya Hospital, Central South

University, Changsha, 4I00II, People's

Republic of China

*These authors contributed equally to this work

Correspondence: Qiong Lu

Department of Pharmacy, the Second

Xiangya Hospital, Central South

University; Institute of Clinical Pharmacy,

Central South University, I39 Middle

Renmin Road, Changsha, Hunan, 4I00II,

People's Republic of China

Tel +86-73I-85292072

Fax +86-73I-85533525

Email christy_luq@csu.edu.cn
Background: SARS-CoV-2 can damage not only the lungs but also the liver and kidney. Most critically ill patients with coronavirus disease 2019 (COVID-19) have liver and kidney dysfunction. We aim to investigate the levels of liver and kidney function indexes in mild and severe COVID-19 patients and their capability to predict the severity of the disease.

Methods: The characteristics and laboratory indexes were compared between patients with different conditions. We applied binary logistic regression to find the independent risk factors of severe patients. Receiver operating characteristic (ROC) analysis was used to predict the severity of COVID-19 using the liver and kidney function indexes.

Results: This study enrolled 266 COVID-19 patients, including 235 mild patients and 31 severe patients. Compared with mild patients, severe patients had lower albumin (ALB) and higher alanine aminotransferase (ALT), aspartate aminotransferase (AST), and urea nitrogen (BUN) (all $\mathrm{p}<0.001)$. Binary logistic regression analysis also identified ALB [OR $=0.273$ (0.079-0.947), $\mathrm{p}=0.041]$ and ALT [OR=2.680 (1.036-6.934), $\mathrm{p}=0.042]$ as independent factors of severe COVID-19 patients. Combining ALB, ALT, BUN, and LDH exhibited the area under ROC at 0.914 , with a sensitivity of $86.7 \%$ and specificity of $83.0 \%$.

Conclusion: COVID-19 patients, especially severe patients, have damage to liver and kidney function. ALT, AST, LDH, and BUN could be independent factors for predicting the severity of COVID-19. Combining the ALB, ALT, BUN, and LDH could predict the transition from mild to severe in COVID-19 patients.

Keywords: COVID-19, liver damage, kidney damage, predictor of disease severity

\section{Introduction}

Coronavirus disease 2019 (COVID-19), caused by the Severe Acute Respiratory Syndrome Corona Virus 2(SARS-CoV-2), is widely spread around the world and has caused significant pressure on the social and impact human health. ${ }^{1}$ Previous studies revealed that SARS-CoV-2 uses the angiotensin-converting enzyme 2 (ACE2) receptor to enter the lungs, ${ }^{2,3}$ which can cause severe lung fibrosis and consolidation, resulting in high mortality in severe cases. ${ }^{4,5}$ Further studies have demonstrated that this virus can also damage the liver ${ }^{6-10}$ and kidneys ${ }^{11-14}$ since ACE2 is also expressed in both organs. ${ }^{15}$ Other possible associated mechanisms of liver and kidney damage include the inflammatory cytokine storm, ${ }^{1,5,16-18}$ druginduced injury, ${ }^{14,19-23}$ chronic liver and kidney disease ${ }^{24-27}$ and other factors, such as hemodynamic changes. ${ }^{28,29}$

Evidence suggests that the incidence of COVID-19 patients liver injury ranged from $14.8 \%$ to $53 \%$, mainly presented by abnormal laboratory indexes including alanine aminotransferase (ALT), aspartate aminotransferase (AST), albumin (ALB), lactate 
dehydrogenase (LDH), and $\alpha$-hydroxybutyricdehydrogenase $(\alpha-\mathrm{HBDH}){ }^{9,22,30,31}$ Moreover, severe cases were more likely to have a severe liver injury than mild patients. ${ }^{7,32}$ In addition, kidney involvement is common in COVID-19 patients who usually present with proteinuria. Especially, severe patients are prone to sepsis-related acute kidney injury (AKI) and hypoperfusion-related AKI. ${ }^{24}$ COVID-19 combined with kidney damage is an independent risk factor for poor prognosis and is associated with high mortality rates in ICU. ${ }^{24,33}$

As a result, we have known that SARS-CoV-2 can damage the liver and kidney function via different mechanisms, and the more serious the disease is, the more serious is the function damage. So far, there has been little discussion about early monitoring of liver and kidney function to predict the patient's condition changes, thereby reducing mortality. Our study focuses on the clinical characteristics of COVID-19 patients' liver and kidney function, aiming to investigate the role of liver and kidney indexes in the transition from mild to severe in COVID-19 patients. We collected and compared the clinical data of mild and severe COVID19 patients, hoping to help improve critically ill patients with COVID-19.

\section{Methods}

\section{Participants}

The inclusion criteria for patients admitted to the Changsha Public Health Treatment Center were tested positive for novel coronavirus nucleic acid in two respiratory specimens, according to the diagnosis and treatment guidelines of COVID-19 in China. ${ }^{34}$ Cases without complete clinical data were excluded from this study. According to the COVID-19 management guidelines in the seventh edition, ${ }^{35}$ we defined the mild patients as follows: (1) the clinical symptoms are mild, and no pneumonia manifestations can be found in imaging; or (2) a patient has symptoms, such as fever and respiratory tract symptoms, and pneumonia manifestations can be seen in imaging. Severe patients were defined as those who meet any of the following criteria: respiratory rate $\geq 30$ breaths $/ \mathrm{min}$; oxygen saturation $\leq 93 \%$ at a rest state; arterial partial pressure of oxygen $\left(\mathrm{PaO}_{2}\right)$ /oxygen concentration $\left(\mathrm{FiO}_{2}\right) \leq 300 \mathrm{~mm} \mathrm{Hg}$; occurrence of respiratory failure requiring mechanical ventilation; the presence of shock; other organ failures that require monitoring and treatment in the Intensive Care Unit. ${ }^{34}$
The liver injury patients were defined as follows: (1) patients diagnosed COVID-19; (2) examined for liver function with one or more of the following abnormalities during treatment, alanine aminotransferase (ALT) $>66 \mathrm{u} / \mathrm{l}$, aspartate aminotransferase $(\mathrm{AST})>46 \mathrm{u} / \mathrm{l}$, total bilirubin $(\mathrm{TBil})>20.5 \mu \mathrm{mol} / \mathrm{l}$. All patients had no abnormal baseline liver function. ${ }^{36}$ The kidney injury patients were defined as follows: (1) patients diagnosed COVID-19; (2) with blood urea nitrogen (BUN) $>7.1 \mathrm{mmol} / \mathrm{L}$ or creatinine $(\mathrm{Cr})>106 \mathrm{~mol} / \mathrm{L} .^{11}$

\section{Data Collection}

We collected the demographic characteristics information and baseline clinical data through the electronic medical record system. The data included patients' age, sex, comorbidities, and related laboratory indicators such as total bilirubin (TB), ALB, ALT, AST, and other indexes. All the laboratory testing values were the values tested for the first time after admission. After treatment, patients whose condition is aggravating, transforming into severe type; then, three days later, their disease index was measured. All patients were anonymous, and all records were deleted after data coding and analysis to protect patients' privacy.

\section{Statistical Analysis}

Statistical analyses were undertaken using SPSS v21.0 (IBM, Armonk, NY, USA). The description of measurement data was expressed as mean \pm standard deviation or median value within the interquartile range. The comparison between the two groups was made using the $t$-test and the Mann-Whitney $U$-test. And the comparison of three independent samples was made using the Kruskal-Wallis $H$-tests. The chi-square test or the Fisher's exact test was used to compare the rates between the two samples. Binary logistic regression was used to analyze the influence of liver and renal indexes on the severity of the disease and calculate the joint factor to draw the joints in the receiver operating curve (ROC). $\mathrm{P}<0.05$ was considered significant.

\section{Results \\ Comparison of Baseline Characteristics Between Three Group Patients}

According to the criteria, we divided the 266 patients into 235 mild patients and 31 severe patients (Table 1). The age of the severe patients was older than that of the mild patients $(57.42 \pm 14.28$ years vs $43.86 \pm 15.71$ years, $\mathrm{p}<0.001)$. 
Table I Baseline Characteristics Between Three Group Patients

\begin{tabular}{|c|c|c|c|c|}
\hline \multirow[t]{2}{*}{ Characteristics } & \multirow[t]{2}{*}{ Mild Group (235) } & \multicolumn{2}{|c|}{ Severe Group (3I) } & \multirow[t]{2}{*}{$P$ value } \\
\hline & & Pre-Severe Group (3I) & After-Severe Group (3I) & \\
\hline Age (years) & $43.86 \pm|5.7|$ & \multicolumn{2}{|l|}{$57.42 \pm 14.28$} & $<0.001$ \\
\hline Sex (female, n\%) & $|2|(5 \mid .49 \%)$ & \multicolumn{2}{|l|}{$13(41.9 \%)$} & 0.317 \\
\hline Smoking & $22(9.4 \%)$ & \multicolumn{2}{|l|}{$5(16.1 \%)$} & 0.241 \\
\hline \multicolumn{5}{|l|}{ Signs and symptoms } \\
\hline Fever & $108(46.35 \%)$ & $27(87.10 \%)$ & $28(90.32 \%)$ & $<0.001$ \\
\hline Cough & $166(70.64 \%)$ & $23(74.19 \%)$ & |2(38.7|\%) & 0.014 \\
\hline Dyspnea & $44(18.72 \%)$ & $13(41.92 \%)$ & $15(48.39 \%)$ & $<0.001$ \\
\hline Diarrhea & $35(\mid 4.89 \%)$ & $\mathrm{I}(3.23 \%)$ & $2(6.46 \%)$ & 0.113 \\
\hline Anorexia & $17(7.23 \%)$ & $10(32.26 \%)$ & $6(19.35 \%)$ & 0.002 \\
\hline Headache & $23(9.79 \%)$ & $4(12.90 \%)$ & $4(12.90 \%)$ & 0.290 \\
\hline \multicolumn{5}{|l|}{ Temperature $\left({ }^{\circ} \mathrm{C}\right)$} \\
\hline$\leq 37.2$ & $102(43.40 \%)$ & $7(22.58 \%)$ & $5(16.13 \%)$ & 0.002 \\
\hline $37.2-38$ & $57(24.26 \%)$ & $6(19.35 \%)$ & II(35.48\%) & 0.299 \\
\hline $38.1-39$ & $46(19.15 \%)$ & $16(51.61 \%)$ & |2(38.7|\%) & $<0.001$ \\
\hline$\geq 39.1$ & $5(2.13 \%)$ & $2(6.46 \%)$ & $3(9.68 \%)$ & 0.047 \\
\hline \multicolumn{5}{|l|}{ Comorbidities } \\
\hline Diabetes & $22(9.36 \%)$ & \multicolumn{2}{|l|}{$3(9.68 \%)$} & 1.000 \\
\hline Hypertension & 35 (14.89\%) & \multicolumn{2}{|l|}{$10(32.26 \%)$} & 0.015 \\
\hline Cerebral infarction & $8(3.40 \%)$ & \multicolumn{2}{|l|}{ I (3.23\%) } & 1.000 \\
\hline Heart disease & $8(3.40 \%)$ & \multicolumn{2}{|l|}{$3(9.68 \%)$} & 0.242 \\
\hline Liver disease & $15(6.38 \%)$ & \multicolumn{2}{|l|}{$3(9.68 \%)$} & 0.760 \\
\hline Chronic obstructive Pulmonary disease & $4(1.70 \%)$ & \multicolumn{2}{|l|}{ I (3.23\%) } & 1.000 \\
\hline Tumor & $2(0.85 \%)$ & \multicolumn{2}{|l|}{$0(0.00 \%)$} & 1.000 \\
\hline \multicolumn{5}{|l|}{ Laboratory indexes } \\
\hline $\mathrm{WBC}\left(\times 10^{9} / \mathrm{L}\right)$ & $5.07(3.86-6.49)$ & $4.3 \mathrm{I}(2.79-4.70)$ & $9.07(6.16-11.73)$ & $<0.001$ \\
\hline $\operatorname{NEUT}\left(\times 10^{9} / \mathrm{L}\right)$ & $3.15(2.37-4.09)$ & $2.76(1.80-3.17)$ & $8.22(73.70-92.10)$ & $<0.001$ \\
\hline NEUT \% & $64.85(59.45-72.43)$ & $68.20(64.00-73.70)$ & $90.30(73.70-92.10)$ & $<0.001$ \\
\hline $\operatorname{LYM}\left(\times 10^{9} / \mathrm{L}\right)$ & $1.27(0.92-1.73)$ & $0.80(0.69-0.97)$ & $0.57(0.47-0.80)$ & $<0.001$ \\
\hline LYM\% & $25.40(18.50-30.00)$ & $22.10(17.40-28.00)$ & $6.20(4.80-19.70)$ & $<0.001$ \\
\hline
\end{tabular}

Note: Statistically significant differences are emboldened.

Abbreviations: WBC, white blood cell; NEUT, neutrophil; LYM, lymphocyte.

Severe patients have a higher proportion of fever $(\mathrm{p}<0.001)$, cough $(\mathrm{p}=0.014)$, dyspnea $(\mathrm{p}<0.001)$, and anorexia $(p=0.002)$ than those of mild patients. The body temperature of the severe patients was higher than that of the mild patients in the range of 38 degrees Celsius $(p<0.001)$. The white blood cell (WBC) and neutrophil (NEU) ratio of severe 
patients is higher than that of mild patients $(\mathrm{p}<0.001)$. The lymphocyte (LYM) ratio of severe patients is lower than that of mild patients $(\mathrm{p}<0.001)$. There was no difference between the severe patients and the mild patients in smoking $(\mathrm{p}=0.241)$, the distribution of $\operatorname{sex}(\mathrm{p}=0.317)$, and the other comorbidities except hypertension.

\section{Comparison of Liver and Kidney Indexes Between Three Group Patients}

By comparing the liver and kidney indexes' values of mild patients and the pre-severe values of severe patients, we found that the severe patients had higher values of AST, $\mathrm{LDH}$, and PT than those of the mild patients (all $\mathrm{p}<0.05$ ). Compared to the liver and kidney indexes' values of mild patients and the after-severe values of severe patients, severe patients had higher values of ALT, AST, LDH, BUN, and DD, and lower values of ALB and APTT (all $\mathrm{p}<0.05$ ). When comparing with the liver and kidney indexes' values of pre-severe and after-severe values of severe patients, we found that with the transition from presevere to severe, the values of $\mathrm{LDH}, \mathrm{BUN}$, and DD were increased; and the values of ALB and APTT were decreased (all $\mathrm{p}<0.05$ ) (Table 2). From the detailed comparison of liver and kidney indexes between mild group and severe group (Table 3), we found that within the range of ALT $<42 \mathrm{u} / \mathrm{L}$, there were 196 mild patients and 19 severe patients. Within the range of ALT $>150 \mathrm{u} / \mathrm{L}$, only 2 mild patients and 3 severe patients. Within the range of AST $>120 \mathrm{u} / \mathrm{L}$, there is only 1 patient with mild disease and 3 patients with severe disease. One hundred eighty-two patients with mild disease and 11 patients with severe disease within the normal range of ALB. There were 43 mild patients and 22 severe patients with LDH over $225 \mathrm{U} / \mathrm{L}$. There were 162 mild patients and 11 severe patients with BUN exceeding $8.2 \mathrm{mmol} / \mathrm{L}$. Other indicators such as TB and $\mathrm{Cr}$ were not statistically different between the two groups.

\section{Comparison of Clinical Laboratory Indexes Between Patients with and without Liver Injury}

Liver injury was defined as increased levels of ALT, AST, and total bilirubin (TB). Of those admitted,38 patients had liver injuries. And they had higher WBC, NEU, DD, AST, LDH, BUN levels and lower Lymphocyte ratio, ALB

Table 2 Comparison of Liver and Kidney Indexes Between Different Conditions of COVID-19 Patients

\begin{tabular}{|c|c|c|c|c|c|c|}
\hline \multirow{2}{*}{$\begin{array}{l}\text { Liver and Kidney } \\
\text { Indexes }\end{array}$} & \multirow[t]{2}{*}{ Mild Group (235) } & \multicolumn{2}{|l|}{ Severe Group (3I) } & \multirow{2}{*}{$\begin{array}{l}\text { PI value } \\
\text { (Mild vs } \\
\text { Pre- } \\
\text { Severe) }\end{array}$} & \multirow{2}{*}{$\begin{array}{l}\text { P2 value } \\
\text { (Mild vs } \\
\text { After- } \\
\text { Severe) }\end{array}$} & \multirow{2}{*}{$\begin{array}{l}\text { P3 value (Pre- } \\
\text { Severe vs } \\
\text { After-Severe) }\end{array}$} \\
\hline & & $\begin{array}{l}\text { Pre-Severe Group } \\
\text { (31) }\end{array}$ & $\begin{array}{l}\text { After-Severe } \\
\text { Group (3I) }\end{array}$ & & & \\
\hline $\mathrm{TB}(\mu \mathrm{mol} / \mathrm{L})$ & $10.87(8.12-15.65)$ & $9.99(6.90-16.45)$ & $13.91(8.61-17.10)$ & 0.342 & 0.220 & 0.147 \\
\hline ALB $(g / L)$ & $38.72(35.83-42.30)$ & $37.30(35.33-39.52)$ & $32.88(29.50-36.50)$ & 0.073 & 0.000 & 0.002 \\
\hline $\mathrm{ALT}(\mathrm{U} / \mathrm{L})$ & $19.85(14.16-29.90)$ & $21.71(16.29-25.80)$ & $24.00(16.20-57.24)$ & 0.685 & 0.029 & 0.145 \\
\hline AST(U/L) & $22.79(17.99-30.62)$ & $30.70(26.28-43.50)$ & $30.00(18.87-55.32)$ & 0.000 & 0.032 & 0.617 \\
\hline $\mathrm{LDH}(\mathrm{U} / \mathrm{L})$ & $\begin{array}{l}167.65(140.15- \\
207.83)\end{array}$ & $\begin{array}{l}197.40(179.00- \\
280.00)\end{array}$ & $\begin{array}{l}295.40(207.55- \\
393.18)\end{array}$ & 0.000 & 0.000 & 0.003 \\
\hline BUN (mmol/L) & $4.16(3.23-5.30)$ & $4.40(3.45-5.08)$ & $6.23(5.19-8.60)$ & 0.632 & 0.000 & 0.000 \\
\hline $\mathrm{Cr}(\mu \mathrm{mol} / \mathrm{L})$ & $53.37(41.50-67.92)$ & $56.48(50.00-74.00)$ & $49.60(41.60-61.00)$ & 0.108 & 0.724 & 0.125 \\
\hline PT (time) & II.70(II.I0-12.50) & $12.20(\mid 1.80-12.70)$ & $12.10(10.88-12.90)$ & 0.031 & 0.368 & 0.659 \\
\hline APTT (time) & $33.10(30.60-35.80)$ & $33.30(29.90-38.30)$ & $30.85(25.88-34.50)$ & 0.529 & 0.010 & 0.038 \\
\hline $\mathrm{DD}(\mathrm{mmol} / \mathrm{L})$ & $0.26(0.14-0.55)$ & $0.3 I(0.14-0.56)$ & $0.52(0.27-1.84)$ & 0.765 & 0.001 & 0.037 \\
\hline
\end{tabular}

Note: Statistically significant differences are emboldened.

Abbreviations: TB, total bilirubin; ALB, albumin; ALT, alanine aminotransferase; AST, aspartate aminotransferase; LDH, lactic dehydrogenase; BUN, blood urea nitrogen; Cr, creatinine; PT, prothrombin time; APTT, activated partial thromboplastin time; DD, D-Dimer. 
Table 3 Detailed Comparison of Liver and Kidney Indexes Between Mild Group and Severe Group

\begin{tabular}{|c|c|c|c|c|c|}
\hline Laboratory Indexes & References & Mild Group (235) & After-Severe Group (3I) & $\mathbf{x}^{2}$ & P-value \\
\hline ALT(U/L) & $0-42$ & $19.85(14.16-29.90)$ & $24.00(16.20-57.24)$ & 24.719 & $<0.001$ \\
\hline$\leq 42$ & & $196(83.4 \%)$ & $19(61.3 \%)$ & & \\
\hline $42-150$ & & $36(15.3 \%)$ & $9(29.0 \%)$ & & \\
\hline$>150$ & & $\mathrm{I}(0.4 \%)$ & $3(9.7 \%)$ & & \\
\hline AST(U/L) & $0-37$ & $22.79(17.99-30.62)$ & $30.00(18.87-55.32)$ & 35.087 & $<0.001$ \\
\hline$\leq 37$ & & $198(84.3 \%)$ & $17(57.8 \%)$ & & \\
\hline $37-120$ & & $34(14.5 \%)$ & $10(32.3 \%)$ & & \\
\hline$>120$ & & $\mathrm{I}(0.4 \%)$ & $4(12.9 \%)$ & & \\
\hline $\mathrm{TB}(\mu \mathrm{mol} / \mathrm{L})$ & $3.4-20.5$ & $10.87(8.12-15.65)$ & $13.91(8.61-17.10)$ & 2.685 & 0.762 \\
\hline$\leq 20.5$ & & $211(89.8 \%)$ & $25(80.6 \%)$ & & \\
\hline $20.5-31.5$ & & $16(6.8 \%)$ & $5(16.1 \%)$ & & \\
\hline$>31.5$ & & $7(3.0 \%)$ & I (3.2\%) & & \\
\hline ALB $(g / L)$ & $35-55$ & $38.72(35.83-42.30)$ & $32.88(29.50-36.50)$ & 72.550 & $<0.001$ \\
\hline$<35$ & & $41(17.4 \%)$ & $20(64.5 \%)$ & & \\
\hline $35-55$ & & $182(77.4)$ & II (35.5\%) & & \\
\hline$\geq 55$ & & 0 & 0 & & \\
\hline $\operatorname{LDH}(U / L)$ & $135-225$ & $167.65(\mid 40.15-207.83)$ & $295.40(207.55-393.18)$ & 52.246 & $<0.001$ \\
\hline$\leq 225$ & & 190 (80.9\%) & $8(25.8 \%)$ & & \\
\hline$>225$ & & $43(18.3 \%)$ & $22(71.0 \%)$ & & \\
\hline BUN (mmol/L) & $2.86-8.2$ & $4.16(3.23-5.30)$ & $6.23(5.19-8.60)$ & 2.813 & $<0.001$ \\
\hline$\leq 8.2$ & & $214(91.1 \%)$ & $20(64.5 \%)$ & & \\
\hline$>8.2$ & & $9(3.8)$ & II (35.5\%) & & \\
\hline $\operatorname{Cr}(\mu \mathrm{mol} / \mathrm{L})$ & $21.5-104$ & $53.37(41.50-67.92)$ & $49.60(41.60-61.00)$ & 0.641 & 0.681 \\
\hline$\leq 104$ & & $226(96.2 \%)$ & $29(93.5 \%)$ & & \\
\hline$>104$ & & $7(3.0 \%)$ & $2(6.5 \%)$ & & \\
\hline
\end{tabular}

Note: Statistically significant differences are emboldened.

Abbreviations: ALT, alanine aminotransferase; AST, aspartate aminotransferase; TB, total bilirubin; ALB, albumin; LDH, lactic dehydrogenase; BUN, blood urea nitrogen; $\mathrm{Cr}$, creatinine.

levels than that of patients without liver injury (all $\mathrm{p}<0.05)$. There was no significant difference between LYM\%, PT, APTT, TB, and Cr (Table 4).

\section{Comparison of Clinical Laboratory Indexes Between Patients with and without Renal Injury}

Renal injury was defined as increased creatinine levels. Of those admitted,18 patients had renal injury. And they had higher DD, LDH, and BUN levels than patients without renal injury (all $\mathrm{p}<0.05$ ). There was no significant difference between WBC, NEU, LYM, PT, APTT, TB, ALB, ALT, AST, and Cr (Table 5).

\section{Binary Logistic Regression Analysis of Laboratory Indexes to Predict the Mild and Severe Patients}

We performed the binary logistic regression analysis to find the independent factors that influence the severity of COVID-19. The results showed that ALB [OR $=0.273$ 
Table 4 Comparison of Clinical Laboratory Indexes Between Patients with and without Liver Injury

\begin{tabular}{|c|c|c|c|}
\hline Clinical Laboratory Indexes & Patients without Liver Injury (228) & Patients with Liver Injury (38) & $P$ value \\
\hline WBC $\left(\times 10^{9} / L\right)$ & $5.11(3.86-6.85)$ & $6.25(4.52-8.91)$ & 0.021 \\
\hline NEUT( $\left.\times 10^{9} / L\right)$ & $3.19(2.37-4.39)$ & $3.91(2.8 I-7.85)$ & 0.020 \\
\hline NEUT\% & 63.97(56.86-72.85) & $66.42(61.00-89.40)$ & 0.024 \\
\hline $\operatorname{LYM}\left(\times 10^{9} / \mathrm{L}\right)$ & $1.20(0.84-1.70)$ & $1.02(0.57-1.50)$ & 0.051 \\
\hline LYM\% & $26.26(|8.90-32.5|)$ & $23.83(6.20-28.88)$ & 0.012 \\
\hline PT (time) & $11.80(11.10-12.70)$ & $11.40(10.98-12.50)$ & 0.483 \\
\hline APTT (time) & $32.60(30.20-35.70)$ & $33.55(27.45-35.45)$ & 0.826 \\
\hline $\mathrm{DD}(\mathrm{mmol} / \mathrm{L})$ & $0.26(0.14-0.56)$ & $0.39(0.24-0.74)$ & 0.015 \\
\hline $\mathrm{TB}(\mu \mathrm{mol} / \mathrm{L})$ & $10.92(8.01-16.20)$ & $11.75(8.64-17.10)$ & 0.419 \\
\hline $\operatorname{ALB}(g / L)$ & $38.45(35.48-42.38)$ & $36.53(32.49-39.15)$ & 0.015 \\
\hline ALT(U/L) & $19.29(13.57-26.40)$ & $53.66(28.79-97.23)$ & $<0.001$ \\
\hline AST(U/L) & $22.38(17.45-28.40)$ & $42.75(24.84-55.34)$ & $<0.001$ \\
\hline LDH(U/L) & $|7| .30(|4| .00-2 \mid 0.50)$ & $206.85(I 70.63-308.20)$ & 0.001 \\
\hline BUN (mmol/L) & $4.20(3.24-5.39)$ & $5.20(4.57-6.55)$ & 0.001 \\
\hline $\mathrm{Cr}(\mu \mathrm{mol} / \mathrm{L})$ & $53.68(4 I .48-67.15)$ & $49.40(4 I .60-67.55)$ & 0.956 \\
\hline
\end{tabular}

Note: Statistically significant differences are emboldened.

Abbreviations: WBC, white blood cell; NEUT, neutrophil; LYM, lymphocyte; PT, prothrombin time; APTT, activated partial thromboplastin time; DD, D-Dimer; TB, total bilirubin; ALB, albumin; ALT, alanine aminotransferase; AST, aspartate aminotransferase; LDH, lactic dehydrogenase; BUN, blood urea nitrogen; Cr, creatinine.

(0.079-0.0.947), $\mathrm{P}=0.041], \quad \mathrm{ALT} \quad[\mathrm{OR}=2.680 \quad(1.036-$ 6.934), $\mathrm{P}=0.042], \quad \mathrm{BUN} \quad[\mathrm{OR}=1.325 \quad(1.081-1.624)$, $\mathrm{P}=0.007], \quad \mathrm{LDH} \quad[\mathrm{OR}=1.005 \quad(1.001-1.008), \quad \mathrm{P}=0.006]$ were independent risk factors of the transition from mild to After-severe condition (Table 6).

\section{The ROC Analysis of Liver and Kidney Indexes to Predict the Mild and Severe Patients}

We analyzed the ROCs of ALT, AST, LDH, and BUN in the mild and after-severe patients (Figure 1, Table 7). Moreover, we also drew the ROC curve of the combined indexes to predict the severity of COVID-19. ALT, AST, $\mathrm{LDH}$, and BUN could independently predict the transition from mild to after-severe in COVID-19 patients (all $\mathrm{p}<0.05)$. LDH exhibited the largest area under the ROC (0.869), with the highest specificity $(90.0 \%)$ and sensitivity (66.5\%). The combination indexes of ALB, ALT, BUN, and LDH exhibited the largest area under the ROC (0.914), with a specificity of $83.0 \%$ and sensitivity of $86.7 \%$.

\section{Discussion}

Numerous reports have shown that the mortality of severe COVID-19 patients was very high. ${ }^{37-39}$ It is urgent to find early indicators for predicting disease exacerbation. Previous studies have shown that the production of inflammatory cytokines and the extension of lung infection were positively correlated with the severity of the disease and could be used as clinical indicators for judging the severity of COVID-19. ${ }^{40-43}$ Our study found that ALT, AST, LDH, and BUN could independently predict the transition from mild to after-severe in COVID-19 patients (all $\mathrm{p}<0.05$ ). Current evidence for mechanisms of liver-kidney injury in SARS-CoV-2 infection is still unclear. Seow et al reported the co-expression of ACE2 and TMPRSS2 in a TROP2+ liver progenitor population and identified a potentially highrisk liver cell-type for viral ingress. ${ }^{44}$ Much of which is based on speculation, case reports, and case series, as shown in Figures 2 and 3, what we know precisely is that ACE2 and TMPRSS2, the host receptor of SARS-CoV-2, exists in the liver (cholangiocytes have higher expression) and kidney, which may explain why SARS-CoV-2 can lead 
Table 5 Comparison of Clinical Laboratory Indicators Between Patients with and without Renal Injury

\begin{tabular}{|c|c|c|c|}
\hline Clinical Laboratory Indexes & Patients without Renal Injury (248) & Patients with Renal Injury (18) & $P$ value \\
\hline $\mathrm{WBC}\left(\times 10^{9} / \mathrm{L}\right)$ & $5.06(3.77-6.84)$ & $5.12(4.18-8.72)$ & 0.268 \\
\hline $\operatorname{NEU}\left(\times 10^{9} / \mathrm{L}\right)$ & $3.17(2.32-4.39)$ & $3.19(2.78-6.72)$ & 0.240 \\
\hline NEUT\% & $65.11(58.80-73.08)$ & $71.59(60.75-82.79)$ & 0.263 \\
\hline $\operatorname{LYM}\left(\times 10^{9} / \mathrm{L}\right)$ & $1.12(0.80-1.62)$ & $0.92(0.61-1.56)$ & 0.367 \\
\hline LYM\% & $25.80(18.52-30.73)$ & 19.95(II.00-30.76) & 0.286 \\
\hline PT (time) & $11.90(11.10-12.60)$ & $12.25(11.38-13.60)$ & 0.093 \\
\hline APTT (time) & $32.70(30.10-35.70)$ & $33.55(31.15-38.08)$ & 0.270 \\
\hline $\mathrm{DD}(\mathrm{mmol} / \mathrm{L})$ & $0.27(0.15-0.56)$ & $0.49(0.17-1.45)$ & 0.049 \\
\hline $\mathrm{TB}(\mu \mathrm{mol} / \mathrm{L})$ & $11.29(8.15-16.43)$ & $10.66(6.38-17.17)$ & 0.400 \\
\hline $\operatorname{ALB}(g / L)$ & $38.31(35.36-4 I .60)$ & $36.12(29.08-42.00)$ & 0.136 \\
\hline $\operatorname{ALT}(\mathrm{U} / \mathrm{L})$ & $20.13(14.55-29.12)$ & $27.18(15.08-45.43)$ & 0.184 \\
\hline AST(U/L) & $23.60(18.84-33.17)$ & $28.00(21.50-41.84)$ & 0.092 \\
\hline $\mathrm{LDH}(\mathrm{U} / \mathrm{L})$ & $180.10(142.63-220.70)$ & $224.35(|80.43-3| 4.25)$ & 0.004 \\
\hline BUN (mmol/L) & $4.29(3.37-5.34)$ & 7.37(4.10-8.95) & 0.001 \\
\hline $\mathrm{Cr}(\mu \mathrm{mol} / \mathrm{L})$ & $54.24(43.15-66.85)$ & $62.46(37.58-120.11)$ & 0.435 \\
\hline
\end{tabular}

Note: Statistically significant differences are emboldened.

Abbreviations: WBC, white blood cell; NEUT, neutrophil; LYM, lymphocyte; PT, prothrombin time; APTT, activated partial thromboplastin time; DD, D-Dimer; TB, total bilirubin; ALB, albumin; ALT, alanine aminotransferase; AST, aspartate aminotransferase; LDH, lactic dehydrogenase; BUN, blood urea nitrogen; $\mathrm{Cr}$, creatinine.

to liver-kidney damage and levels of liver enzymes and kidney bio-makers such as creatinine and BUN increased. $^{45,46}$ The distribution and expression of ACE2 and TMPRSS2 are strongly associated with the target organ of the SARS-CoV-2 infection. ${ }^{47,48}$ BUN is one of the common indicators of kidney function, and BUN levels increase during kidney failure. Studies have shown that patients with severe-critical disease had more laboratory evidence indicating a cytokine storm responsible for developing severe pneumonia, organ damage, and abnormal laboratory data. Abnormal blood rheology and the drug's toxic effect could explain why BUN and liver enzymes can be independent predictors for COVID-19 patients. $^{49}$ The combination indexes of ALB, ALT, BUN, and LDH exhibited the largest area under the ROC $(0.914)$, with the specificity $(83.0 \%)$ and sensitivity $(86.7 \%)$, which means that the liver and kidney combined indexes could also predict the severity of COVID-19 patients. These findings may help to improve critically ill COVID-19 patients.

In this study, we also find that the average age of severe patients ( 57.42 years) is higher than that of mild patients (43.86 years). Severe patients showed a higher percentage of fever, cough, dyspnea, and anorexia than mild patients. And severe patients show higher

Table 6 Binary Logistic Regression Analysis of Laboratory Indexes to Predict the Mild and After-Severe Patients

\begin{tabular}{|l|l|l|l|l|l|}
\hline Laboratory Indexes & Regression Coefficient & Standard Deviation & OR & $\mathbf{9 5 \%}$ Cl & P value \\
\hline ALB $(\mathrm{g} / \mathrm{L})$ & -0.205 & 0.059 & 0.815 & $0.725-0.915$ & $\mathbf{0 . 0 0 1}$ \\
ALT(U/L) & 0.009 & 0.004 & 1.009 & $1.002-1.016$ & $\mathbf{0 . 0 1 3}$ \\
BUN (mmol/L) & 0.281 & 0.104 & 1.325 & $1.081-1.624$ & $\mathbf{0 . 0 0 7}$ \\
LDH(U/L) & 0.005 & 0.002 & 1.005 & $1.001-1.008$ & $\mathbf{0 . 0 0 6}$ \\
\hline
\end{tabular}

Note: Statistically significant differences are emboldened.

Abbreviations: ALB, albumin; ALT, alanine aminotransferase; BUN, blood urea nitrogen; LDH, lactic dehydrogenase; OR, odds ratio; Cl, confidence intervals. 


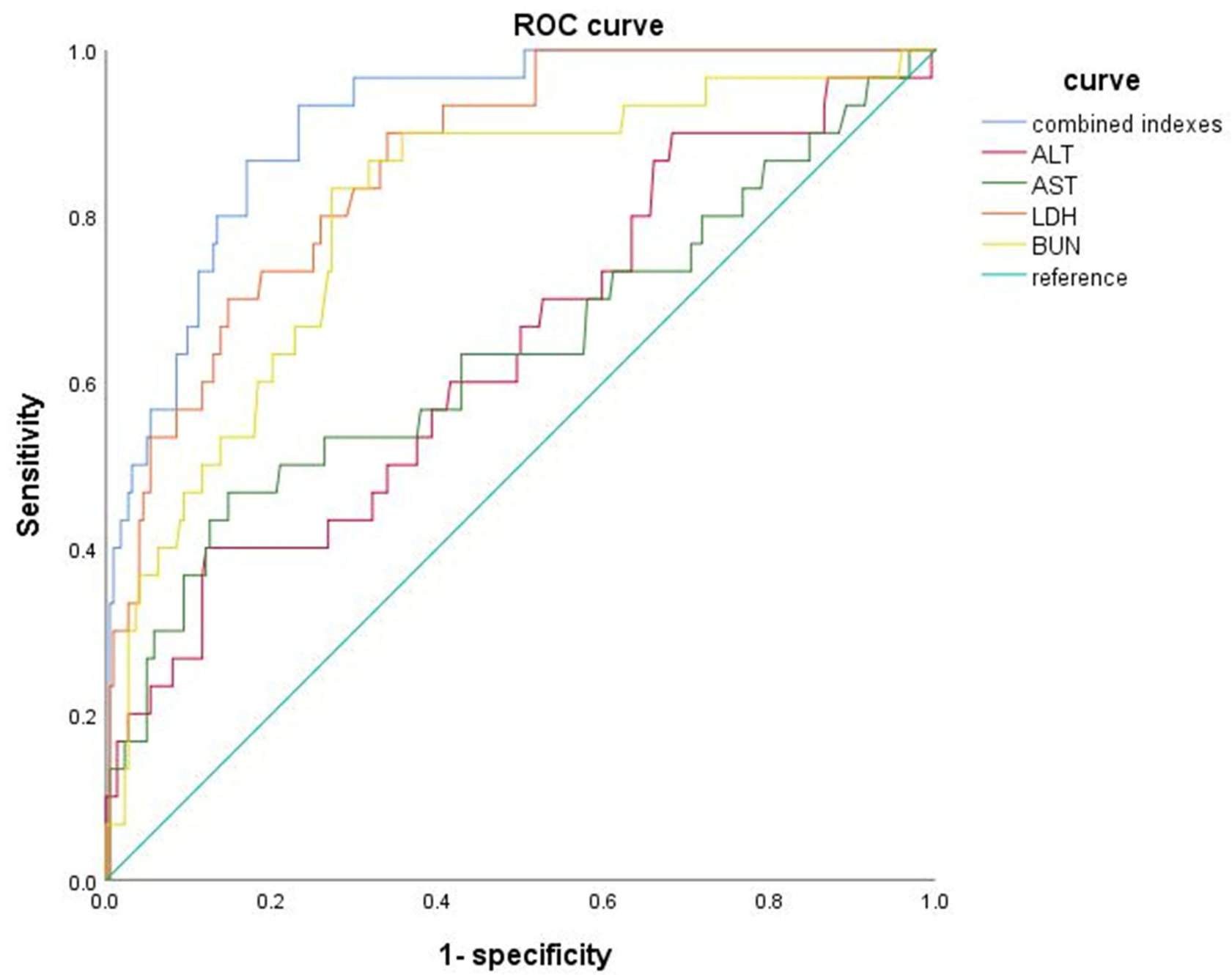

Figure I The ROC analysis of liver and kidney indexes to predict the mild and severe patients.

inflammatory responses, such as leukocyte rise, neutropenia, and lymphocyte decrease. These results are in accordance with studies indicating that older patients are more likely to turn into severe patients ${ }^{50,51}$ and a larger proportion of severe patients showed high fever, cough, and dyspnea. ${ }^{52}$ Moreover, inflammatory responses in severe patients were more intense. ${ }^{16,18,43,53}$
A previous study showed that more than one-third of SARS-COV-2 patients had abnormal liver function. ${ }^{9}$ A review published by Kukla et al showed that a large number of studies indicated that liver abnormalities were mainly characterized by mild to moderate elevation of aminotransferase, hypoproteinemia, and prolonged prothrombin time. ${ }^{54}$ Our study also found that the liver and

Table 7 The ROC Analysis of Liver and Kidney Indexes to Predict the Mild and Severe Patients

\begin{tabular}{|l|l|l|l|l|l|l|}
\hline Indexes & AUC (95\% Cl) & Critical Value & Sensitivity & Specificity & Jordan Index & P value \\
\hline ALT(U/L) & $0.619(0.506 \sim 0.733)$ & 46.56 & 0.387 & 0.884 & $0.27 I$ & 0.031 \\
AST(U/L) & $0.618(0.492 \sim 0.74 I)$ & 37.43 & 0.452 & 0.854 & 0.306 & 0.032 \\
LDH(U/L) & $0.869(0.808 \sim 0.930)$ & 189.2 & 0.900 & 0.665 & 0.565 & $<0.001$ \\
BUN (mmol/L) & $0.800(0.717 \sim 0.883)$ & 4.89 & 0.871 & 0.682 & 0.553 & $<0.001$ \\
Combined indexes & $\mathbf{0 . 9 1 4 ( 0 . 8 6 8 - 0 . 9 5 9 )}$ & 0.023 & 0.867 & 0.830 & 0.697 & $<0.001$ \\
\hline
\end{tabular}

Note: Statistically significant differences are emboldened.

Abbreviations: ALT, alanine aminotransferase; AST, aspartate aminotransferase; LDH, lactic dehydrogenase; BUN, blood urea nitrogen; ROC, receiver operating characteristic; AUC, area under curve. 


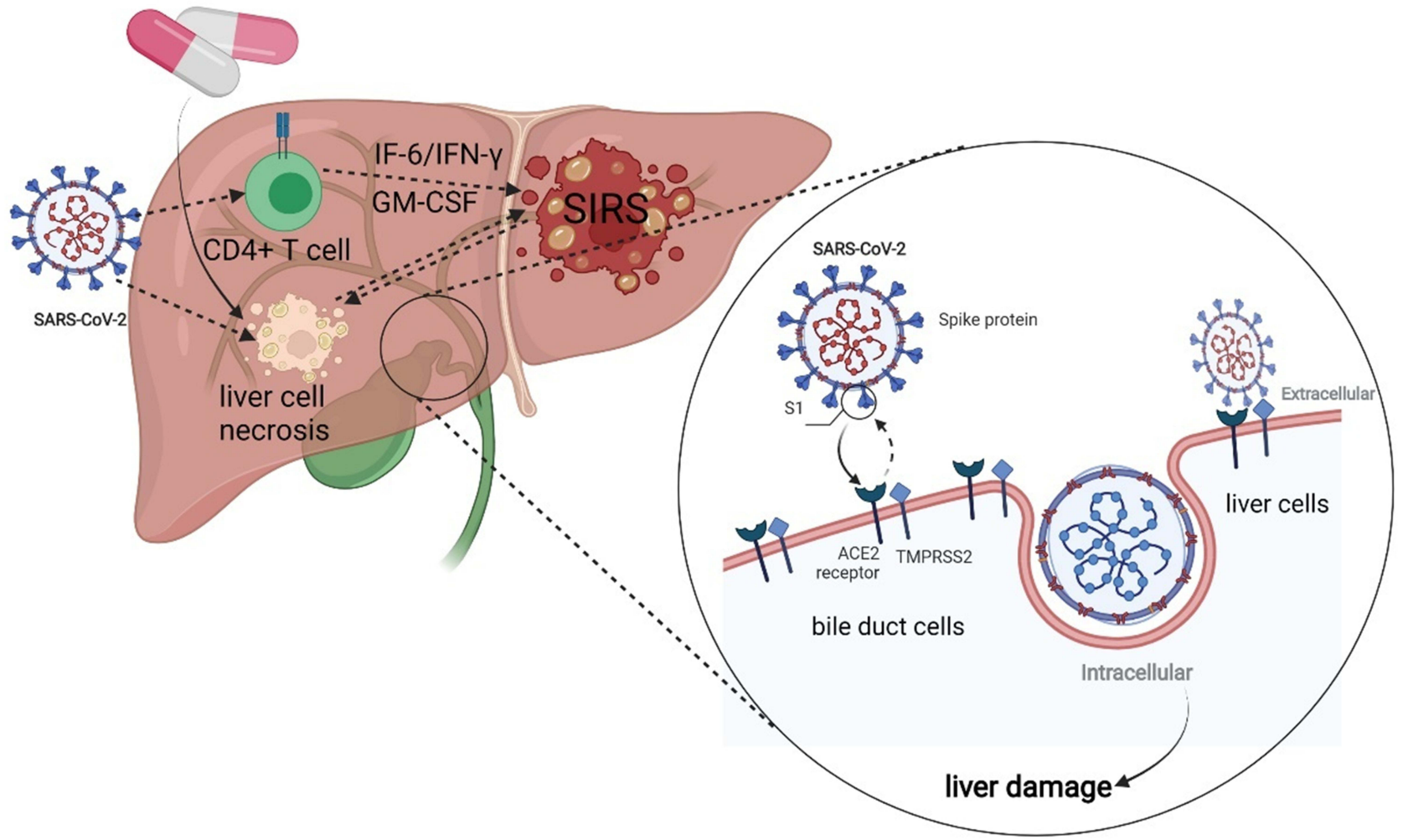

Figure 2 The possible mechanism of hepatocyte injury in COVID-19 patients: SARS-CoV-2 enters hepatocytes through human angiotensin converting enzyme 2(ACE2) and TMPRSS2, leading to denaturation and necrosis of hepatocytes and subsequent accumulation of bile acids. The pathogenic $T$ cells are rapidly activated to produce proinflammatory factors such as granulocyte-macrophage colony stimulating factor (GM-CS F), interleukin (IL)-6, which induces inflammatory "storms “. And drugs may also cause drug-induced liver damage.

kidney indexes of patients were abnormal. Compared with mild patients, the level of ALB in severe patients was decreased, and the levels of ALT, AST, LDH, and BUN in severe patients were increased (all $\mathrm{p}<0.001$ ). Binary logistic regression analysis of laboratory indexes suggests that ALB and ALT may be risk factors for patients' transformation from mild to severe.

Our study also compared with other laboratory indicators in COVID-19 patients with and without liver injury. The results found that patients with COVID-19 liver injury had elevated neutrophils, decreased lymphocytes, and decreased albumin. This result may be explained by the fact that SARS-CoV-2 can damage hepatocytes by binding to the ACE2 receptors of hepatocytes, which leads to liver enzyme abnormalities. ${ }^{6}$ The pathophysiological understanding of COVID-19related kidney injury is yet to be elucidated. Several mechanisms are possibly involved in kidney injury during SARS-CoV-2 infection, including direct invasion of SARS-CoV-2 into the renal parenchyma, an imbalanced RAAS and microthrombosis but also kidney injury secondary to hemodynamic instability, inflammatory cytokines, and the consequences of therapeutics that are used in ICU (nephrotoxic drugs, mechanical ventilation). ${ }^{55-57}$ The images are presented in Figure 3. We also compared changes in laboratory indicators in patients with and without kidney damage. We found that the APTT of kidney injury patients was significantly prolonged, CRP also specifically increased, and the condition of kidney injury patients was often accompanied by hematuria. These results could be attributed to SARS-COV-2 infection of the liver leading to abnormal $\mathrm{APTT}^{58}$ and elevated CRP, and by the damage the renal function to cause hematuria. $^{24}$ D-dimer is a marker for detecting thromboembolic processes and is sensitive to the high risk of thromboembolism. We found that D-dimer was significantly elevated in patients with severe disease. It is speculated that they are related to liver-kidney injury and severe infection. These mechanisms exacerbate one another, resulting in the development of the patient's condition worsened.

There were some limitations in our study. First, this is a retrospective single-center study with a relatively small 


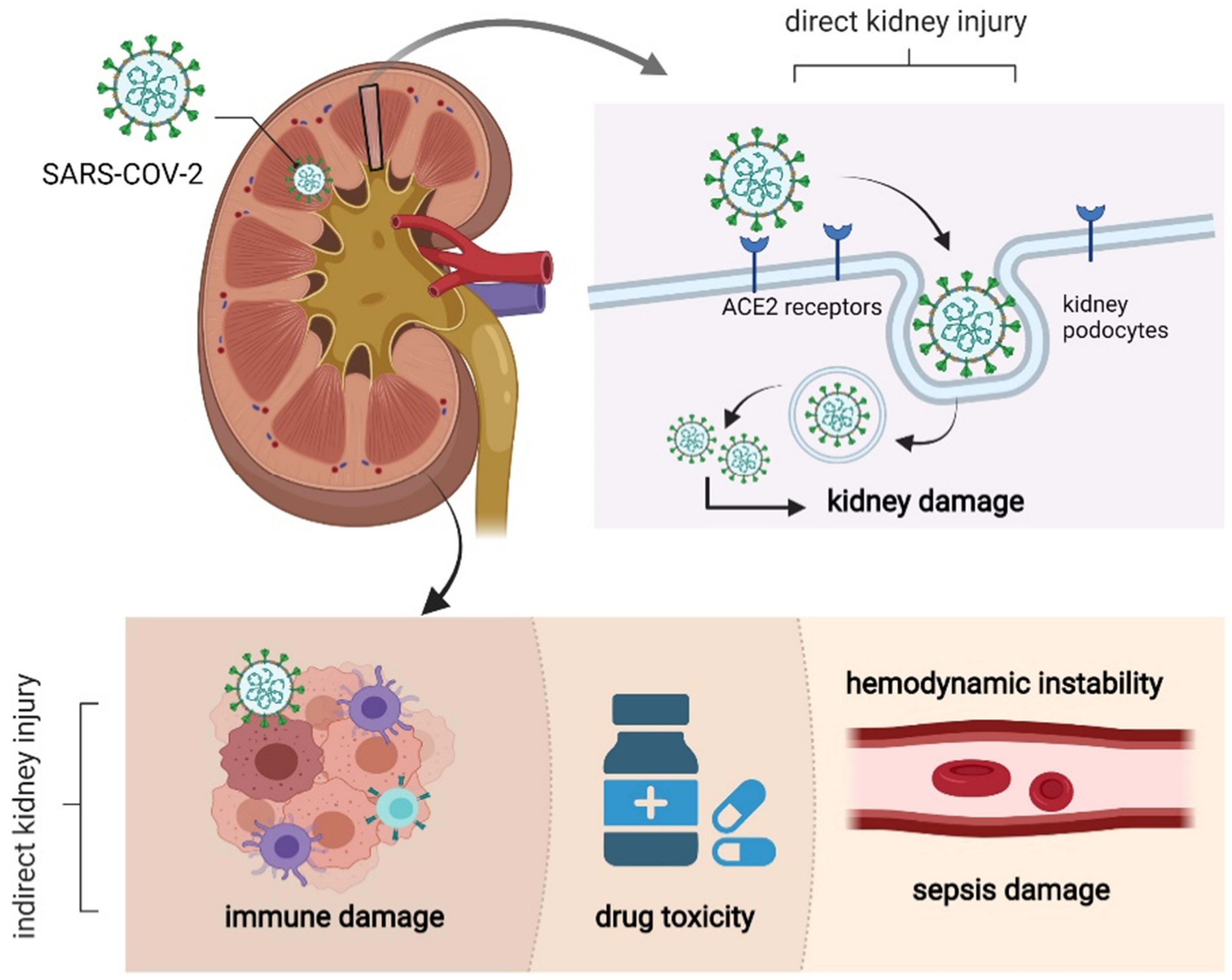

Figure 3 The possible mechanism of kidney injury in COVID-19 patients: SARS-CoV-2 enters kidney cells through human angiotensin converting enzyme 2(ACE2), resulting in degeneration and necrosis of kidney cells. Immune injury, sepsis-related kidney injury, hypovolemic renal hypoperfusion and drug-related kidney injury are all possible mechanisms of kidney injury.

sample size. The establishment of a larger database would better assess the liver and kidney indexes in COVID-19 patients. Second, how does the virus affect the pathophysiological mechanisms of liver and kidney function in patients deserves further study.

\section{Conclusions}

In conclusion, COVID-19 patients, especially severe patients, have damage to liver and kidney function. ALT, AST, LDH, and BUN could be independent factors for predicting the severity of COVID-19. Combining the ALB, ALT, BUN, and L DH together could predict the transition from mild to severe in COVID-19 patients.

\section{Data Sharing Statement}

The data analyzed during this study are available from the corresponding author on reasonable request.

\section{Ethics Approval and Consent to Participate}

The Ethics Committee of the First Hospital of Changsha approved this study. Informed consents were obtained from patients or guardians and the registration number is KL2020005.

\section{Declaration of Submission}

We declare that the paper has not been submitted to another journal and has not been published in whole or in part elsewhere previously. 


\section{Acknowledgments}

We thank the supported grants of the novel coronavirus pneumonia major project of Hunan (2020SK3014) and novel coronavirus pneumonia major project of Changsha Science and technology project (kq2001017). We pay high respects to the medical staff at the front line of the COVID-19 epidemic.

\section{Author Contributions}

All authors made a significant contribution to the work reported, whether that is in the conception, study design, execution, acquisition of data, analysis and interpretation, or in all these areas; took part in drafting, revising or critically reviewing the article; gave final approval of the version to be published; have agreed on the journal to which the article has been submitted; and agree to be accountable for all aspects of the work.

\section{Funding}

This study was supported by the grants of the novel coronavirus pneumonia major project of Hunan (2020SK3014), novel coronavirus pneumonia major project of Changsha Science and technology project (kq2001017) and the Planned Science and Technology Innovation Project of Hunan Province, China (2018SK50503).

\section{Disclosure}

We declare that we have no conflicts of interest.

\section{References}

1. Wei M, Yang N, Wang F, Zhao G, Gao H, Li Y. Epidemiology of coronavirus disease 2019(COVID-19) caused by SARS-CoV-2. Disaster Med Public Health Prep. 2020;14:1-27.

2. Rico-Mesa JS, White A, Anderson AS. Outcomes in patients with COVID-19 infection taking ACEI/ARB. Curr Cardiol Rep. 2020;22 (5):31. doi:10.1007/s11886-020-01291-4

3. Velavan TP, Meyer CG. The COVID-19 epidemic. Trop Med Int Health. 2020;25(3):278-280. doi:10.1111/tmi.13383

4. Xu X, Chen P, Wang J, et al. Evolution of the novel coronavirus from the ongoing Wuhan outbreak and modeling of its spike protein for risk of human transmission. Science China Press. 2020;63(3):52.

5. Ge H, Wang X, Yuan X, et al. The epidemiology and clinical information about COVID-19. Eur J Clin Microbiol Infect Dis. 2020;39 (6):1011-1019. doi:10.1007/s10096-020-03874-z

6. Wang Y, Liu S, Liu H, et al. SARS-CoV-2 infection of the liver directly contributes to hepatic impairment in patients with COVID-19. J Hepatol. 2020;73(4):807.

7. Cardoso FS, Pereira R, Germano N. Liver injury in critically ill patients with COVID-19: a case series. Crit Care. 2020;24(1):190. doi:10.1186/s13054-020-02924-4

8. Chen P, Zhou B. Clinical Characteristics of COVID-19 in Patients With Liver Injury. Clin Gastroenterol Hepatol. 2020;18 (12):2846-2847. doi:10.1016/j.cgh.2020.04.043
9. Fan Z, Chen L, Li J, et al. Clinical Features of COVID-19-related liver functional abnormality. Clin Gastroenterol Hepatol. 2020;18 (7):1561-1566. doi:10.1016/j.cgh.2020.04.002

10. Xu L, Liu J, Lu M, Yang D, Zheng X. Liver injury during highly pathogenic human coronavirus infections. Liver Int. 2020;40 (5):998-1004. doi:10.1111/liv.14435

11. Liu Y, Qi FY, Wei L, Cheng QL. [Clinical analysis of kidney injury in patients with COVID-19]. Zhonghua Yi Xue Za Zhi. 2020;100:E022. Chinese.

12. Fanelli V, Fiorentino M, Cantaluppi V, et al. Acute kidney injury in SARS-CoV-2 infected patients. Crit Care. 2020;24(1):155. doi:10.1186/s13054-020-02872-z

13. Post A, den Deurwaarder ESG, Bakker SJL, et al. Kidney Infarction in Patients With COVID-19. Am J Kidney Dis. 2020;76(3):431-435. doi:10.1053/j.ajkd.2020.05.004

14. Su H, Yang M, Wan C, et al. Renal histopathological analysis of 26 postmortem findings of patients with COVID-19 in China. Kidney Int. 2020;98(1):219-227. doi:10.1016/j.kint.2020.04.003

15. Donoghue M, Hsieh F, Baronas E, et al. A novel angiotensin-converting enzyme-related carboxypeptidase (ACE2) converts angiotensin I to angiotensin 1-9. Circ Res. 2000;87(5):E1-9. doi:10.1161/01.RES.87.5.e1

16. Zhang Y, Gao Y, Qiao L, Wang W, Chen D. Inflammatory response cells during acute respiratory distress syndrome in patients with coronavirus disease 2019 (COVID-19). Ann Intern Med. 2020;173 (5):402-404. doi:10.7326/L20-0227

17. Taghizadeh-Hesary F, Akbari H. The powerful immune system against powerful COVID-19: a hypothesis. Med Hypotheses. 2020;140:109762. doi:10.1016/j.mehy.2020.109762

18. Yonggang Z, Binqing F, Xiaohu Z, Dongsheng W, Changcheng Z. Pathogenic $T$ cells and inflammatory monocytes incite inflammatory storm in severe COVID-19 patients. National Ence Review. 2020;24:587.

19. Olry A, Meunier L, Delire B, Larrey D, Horsmans Y, Le Louet H. Druginduced liver injury and COVID-19 Infection: the rules remain the same. Drug Saf. 2020;43(7):615-617. doi:10.1007/s40264-020-00954-z

20. Muhovic D, Bojovic J, Bulatovic A, et al. First case of drug-induced liver injury associated with the use of tocilizumab in a patient with COVID-19. Liver Int. 2020;40:1901.

21. Sise ME, Baggett MV, Shepard JO, Stevens JS, Rhee EP. Case 17-2020: a 68-year-old man with covid-19 and acute kidney injury. $N$ Engl $J$ Med. 2020;382(22):2147-2156. doi:10.1056/ NEJMcpc2002418

22. Chen T, Wu D, Chen $\mathrm{H}$, et al. Clinical characteristics of 113 deceased patients with coronavirus disease 2019: retrospective study. BMJ. 2020;368:m1091. doi:10.1136/bmj.m1091

23. Rismanbaf A, Zarei S. Liver and Kidney Injuries in COVID-19 and Their Effects on Drug Therapy; a Letter to Editor. Arch Acad Emerg Med. 2020;8(1):e17.

24. Hassanein M, Thomas G, Taliercio J. Management of acute kidney injury in COVID-19. Cleve Clin J Med. 2020.

25. Cheng Y, Luo R, Wang $\mathrm{K}$, et al. Kidney disease is associated with in-hospital death of patients with COVID-19. Kidney Int. 2020;97 (5):829-838. doi:10.1016/j.kint.2020.03.005

26. Rabb H. Kidney diseases in the time of COVID-19: major challenges to patient care. J Clin Invest. 2020;130(6):2749-2751. doi:10.1172/ JCI138871

27. Ronco C, Reis T, Husain-Syed F. Management of acute kidney injury in patients with COVID-19. Lancet Respir Med. 2020;8(7):738-742. doi:10.1016/S2213-2600(20)30229-0

28. Su TH, Kao JH. The clinical manifestations and management of COVID-19-related liver injury. J Formos Med Assoc. 2020;119 (6):1016-1018. doi:10.1016/j.jfma.2020.04.020

29. Barros Camargo L, Quintero Marzola ID, Cárdenas Gómez JC, Mendoza Daza LT, Quintana Pájaro L. Acute kidney injury associated with COVID-19: another extrapulmonary manifestation. Int Urol Nephrol. 2020;52(7):1403-1404. doi:10.1007/s11255-02002507-w 
30. Zhao D, Yao F, Wang L, et al. A comparative study on the clinical features of COVID-19 pneumonia to other pneumonias. Clin Infect Dis. 2020.

31. Huang C, Wang Y, Li X, et al. Clinical features of patients infected with 2019 novel coronavirus in Wuhan, China. Lancet. 2020;395 (10223):497-506. doi:10.1016/S0140-6736(20)30183-5

32. Li J, Fan JG. Characteristics and Mechanism of Liver Injury in 2019 Coronavirus Disease. J Clin Transl Hepatol. 2020;8(1):13-17. doi:10.14218/JCTH.2020.00019

33. Staico MF, Zaffanello M, Di Pietro G, Fanos V, Marcialis MA. The kidney in COVID-19: protagonist or figurant? Panminerva Med. 2020.

34. Zhang S. Novel Coronavirus Infected Pneumonia Treatment Scheme (Trial Seventh Edition) [Z]. Clin Drug Investi. 2020;33:1-6

35. Office of the State Health and Health Commission OotSAoTCM: Diagnosis and treatment of new coronary pneumonia (Trial Version 7)[EB/OL]; 2020. Available from: http://www.nhc.gov.cn/yz[[J]. Accessed July 27, 2021.

36. Ye Z, Song B. Liver injury in COVID-19: diagnosis and associated factors. Liver Int. 2020;40(8):2040-2041. doi:10.1111/liv.14501

37. Ottosson F, Baco E, Lauritzen PM, Rud E. The prevalence and locations of bone metastases using whole-body MRI in treatment-naive intermediate- and high-risk prostate cancer. Eur Radiol. 2020;31:2474.

38. Ye Q, Wang B, Mao J. The pathogenesis and treatment of the 'Cytokine Storm' in COVID-19. J Infect. 2020;80(6):607-613. doi:10.1016/j.jinf.2020.03.037

39. Zhang C, Wu Z, Li JW, Zhao H, Wang GQ. Cytokine release syndrome in severe COVID-19: interleukin-6 receptor antagonist tocilizumab may be the key to reduce mortality. Int $J$ Antimicrob Agents. 2020;55(5):105954. doi:10.1016/j.ijantimicag.2020.105954

40. Felsenstein S, Herbert JA, McNamara PS, Hedrich CM. COVID19Immunology and treatment options. Clin Immunol. 2020;215:108448. doi:10.1016/j.clim.2020.108448

41. Liu F, Li L, Xu M, et al. Prognostic value of interleukin-6, C-reactive protein, and procalcitonin in patients with COVID-19. J Clin Virol. 2020;127:104370. doi:10.1016/j.jcv.2020.104370

42. Yang Y, Shen C, Li J, et al. Plasma IP-10 and MCP-3 levels are highly associated with disease severity and predict the progression of COVID-19. J Allergy Clin Immunol. 2020;146(1):119-127.e4. doi:10.1016/j.jaci.2020.04.027

43. Zhu Z, Cai T, Fan L, et al. Clinical value of immune-inflammatory parameters to assess the severity of coronavirus disease 2019. Int J Infect Dis. 2020;95:332-339. doi:10.1016/j.ijid.2020.04.041

44. Seow J, Zhou Y, Hua J, et al. The scRNA-seq Expression Profiling of the Receptor ACE2 and the Cellular Protease TMPRSS2 Reveals Human Organs Susceptible to SARS-CoV-2 Infection. Int J Environ Res Public Health. 2021;18(1):284. doi:10.3390/ijerph18010284

45. Amiri-Dashatan N, Koushki M, Ghorbani F, Naderi N. Increased inflammatory markers correlate with liver damage and predict severe COVID-19: a systematic review and meta-analysis. Gastroenterol Hepatol Bed Bench. 2020;13(4):282-291.
46. Chen LY, Chu HK, Bai T, et al. Liver damage at admission is an independent prognostic factor for COVID-19. J Dig Dis. 2020;21 (9):512-518. doi:10.1111/1751-2980.12925

47. Kumar A, Faiq MA, Pareek V, et al. Relevance of SARS-CoV-2 related factors ACE2 and TMPRSS2 expressions in gastrointestinal tissue with pathogenesis of digestive symptoms, diabetes-associated mortality, and disease recurrence in COVID-19 patients. Med Hypotheses. 2020;144:110271. doi:10.1016/j.mehy.2020.110271

48. Marjot T, Webb GJ, Barritt A, et al. COVID-19 and liver disease: mechanistic and clinical perspectives. Nat Rev Gastroenterol Hepatol. 2021;18(5):348-364. doi:10.1038/s41575-021-00426-4

49. Shokri Afra H, Amiri-Dashatan N, Ghorbani F, Maleki I, RezaeiTavirani M. Positive association between severity of COVID-19 infection and liver damage: a systematic review and meta-analysis. Gastroenterol Hepatol Bed Bench. 2020;13(4):292-304.

50. Chen T, Dai Z, Mo P, et al. Clinical characteristics and outcomes of older patients with coronavirus disease 2019 (COVID-19) in Wuhan, China (2019): a single-centered, retrospective study. J Gerontol a Biol Sci Med Sci. 2020;75(9):1788-1795. doi:10.1093/gerona/ glaa089

51. Zhou F, Yu T, Du R, et al. Clinical course and risk factors for mortality of adult inpatients with COVID-19 in Wuhan, China: a retrospective cohort study. Lancet. 2020;395(10229):1054-1062. doi:10.1016/S0140-6736(20)30566-3

52. Zhang JJ, Dong X, Cao YY, et al. Clinical characteristics of 140 patients infected with SARS-CoV-2 in Wuhan, China. Allergy. 2020;75(7):1730-1741. doi:10.1111/all.14238

53. Grasselli G, Zangrillo A, Zanella A, et al. Baseline Characteristics and Outcomes of 1591 Patients Infected With SARS-CoV-2 Admitted to ICUs of the Lombardy Region, Italy. JAMA. 2020;323 (16):1574-1581. doi:10.1001/jama.2020.5394

54. Kukla M, Skonieczna-Zydecka K, Kotfis K, et al. COVID-19, MERS and SARS with concomitant liver injury-systematic review of the existing literature. J Clin Med. 2020;9(5):1420. doi:10.3390/ jcm9051420

55. Pineiro GJ, Molina-Andujar A, Hermida E, et al. Severe acute kidney injury in critically ill COVID-19 patients. J Nephrol. 2021;45:587.

56. Sang L, Chen S, Zheng X, et al. The incidence, risk factors and prognosis of acute kidney injury in severe and critically ill patients with COVID-19 in mainland China: a retrospective study. BMC Pulm Med. 2020;20(1):290. doi:10.1186/s12890-020-01305-5

57. Ghosn M, Attallah N, Badr M, et al. Severe Acute Kidney Injury in Critically Ill Patients with COVID-19 Admitted to ICU: incidence, Risk Factors, and Outcomes. J Clin Med. 2021;10(6):1217. doi: $10.3390 / \mathrm{jcm} 10061217$

58. Wan S, Xiang Y, Fang W, et al. Clinical features and treatment of COVID-19 patients in northeast Chongqing. J Med Virol. 2020;92 (7):797-806. doi:10.1002/jmv.25783
Infection and Drug Resistance

\section{Publish your work in this journal}

Infection and Drug Resistance is an international, peer-reviewed openaccess journal that focuses on the optimal treatment of infection (bacterial, fungal and viral) and the development and institution of preventive strategies to minimize the development and spread of resistance. The journal is specifically concerned with the epidemiology of antibiotic resistance and the mechanisms of resistance development and diffusion in both hospitals and the community. The manuscript management system is completely online and includes a very quick and fair peerreview system, which is all easy to use. Visit http://www.dovepress.com/ testimonials.php to read real quotes from published authors. 